\title{
Family Histories, Family Stories and Family Secrets: Late Discoveries of Being Adopted
}

\author{
Gary Clapton
}

check for

updates

Citation: Clapton, Gary. 2021. Family Histories, Family Stories and Family Secrets: Late Discoveries of Being Adopted. Genealogy 5: 105. https://doi.org/10.3390/ genealogy5040105

Received: 9 November 2021 Accepted: 3 December 2021 Published: 8 December 2021

Publisher's Note: MDPI stays neutral with regard to jurisdictional claims in published maps and institutional affiliations.

Copyright: (C) 2021 by the author. Licensee MDPI, Basel, Switzerland. This article is an open access article distributed under the terms and conditions of the Creative Commons Attribution (CC BY) license (https:/ / creativecommons.org/licenses/by/ $4.0 /)$.
Social Work Department, University of Edinburgh, Edinburgh EH8 9LD, UK; gary.clapton@ed.ac.uk

\begin{abstract}
This paper reviews what we know about the experiences of adopted people who discover in later-life that they are adopted. It begins by discussing how and why various facets of the adoption experience have come to the fore over the 20th and 21st century time span of contemporary adoption. The paper concludes with the fact that research on the late discovery of adoption is in its infancy. It also points to parallels that will exist for people who have been conceived by anonymous donation and raises additional areas for possible research.
\end{abstract}

Keywords: adoption; late-discovery; family secrets; shock and losses

\section{Introduction}

Any critical review of the history of modern adoption (that is, 20th and 21st adoption) would have to point out that the gaze of curiosity, professional attention and research has lighted upon different people and practices at different times. Broadly speaking, in the decades after legislation formalised adoption across much of the Anglophone nations, the focus was upon couples who wished to adopt and subsequently were setting out on adoptive parenthood. Knight's (1941) paper, 'Some Problems in Selecting and Rearing Adopted Children' is one example. In the 1950s, once adoptive families had been constituted and parenting adopted children had begun to present unique challenges, the focus became the adopted child and relations within his or her adoptive family (Barbara Raleigh begins her 1954 paper: 'David, age six, is an adopted child and a troubled child' (Raleigh 1954, p. 53)). Later, as adopted children entered adolescence and problems filtered through from practitioners, research interest grew in this field. In his well-known work on genealogical bewilderment, Sants wrote of 'A characteristic of the genealogically bewildered, particularly from adolescence onwards, is their relentless pursuit of the facts of their origin' (Sants 1964, p. 139).

From the 1970s onwards, the adult experiences of these children of the adoptions of 1940s and 1950s began to find their way into conferences, writings and books. ${ }^{1}$ Special attention to searching and contact with birth families was prominent, and works appeared entitled, for example, The Search for Anna Fisher (1973) and A Time to Search: The Moving and Dramatic Stories of Adoptees in Search of Their Natural Parents (1977). ${ }^{2}$ In the same broad chronological period, the birth mothers whose children were adopted in the 1940s and 1950s began to find their voices: Birthmark and Death by Adoption both came out in 1979 and are just two that heralded the opening of a floodgate of birth mother's accounts.

A rise in interest in reunions between adopted people and birth mothers in the 1990s corresponded with the alignment of the years of the highest number of adoptions in the UK (late 1960s) and that of the ages of adopted people most likely to seek contact-their late twenties (Clapton 1996).

Very broad brush, it is understood. Yet, over the last 70 years of adoption as we know it, attention to people and events in adoption seems to wax and wane connected to internal dynamics such as the age and capacity when adopted people are able to publicly express their experiences and when a birth mother can find her voice and get it into print but also, 
as indicated, external social factors - the 'boom' years of baby adoptions (the late 1960s) can be connected to a period 20 years later when interest began to grow and attention was paid to meetings between the children (now adult) and their birth parents. However, more simply, life span events, e.g., there was relatively little attention to adopted adults in the early years of modern adoption, instead, as indicated above, writings on adjusting to being an adoptive parent and raising an adoptive child can be associated with a growth 15 years later in attention to the problems of adolescents who are adopted. Certainly today, when most children are adopted from state care, it can be seen that much of the broad adoption discourse is taken up with engaging with the struggles of these children and their adoptive families. This somewhat impressionistic view of attentions and gazes in adoption should also note the temporary coming into focus of others such as birth fathers and other birth relatives such as brothers and sisters, and events and processes such as the long-term outcomes of reunions between adopted adults and their birth parents. ${ }^{3}$

Any critical history will always be subjective and selective. Some phases and periods overlap. There will be precursors. For example, McWhinnie was researching and writing on the experiences of adopted adults in the late 1950s. Her successful 1960 doctoral thesis was entitled A Study of adoption: The Social Circumstances and Adjustment in Adult Life of 58 adopted children (https: / / www.ed.ac.uk/alumni/services/notable-alumni/alumni-inhistory / alexina-mcwhinnie (accessed on 31 October 2021)). Individual choice has featured in compiling this paper. Pelz notes, 'The logic of narration is more fictional than scientific' (Pelz 1990, p. 765), and so it will be for any history of adoption especially one that sets out to be critical. However, this is not the subject of this paper, but in the author's opinion, a necessary introduction to the main topic, the late discovery of being adopted. In 2009, Riley noted the lack of attention to late discovery, and since then there has been an increase in professional and academic attention (see below) together with the emergence of support networks such as Facebook groups. Https://en-gb.facebook.com/groups/latediscoveries/ (accessed on 31 October 2021) founded in 2011 is just one example. The secrecy that is baked into adoption, in a sense, is a 'gift' that keeps on giving. Down through the decades, the various struggles and challenges (and the pain) that have been touched on above are the fruits of subterfuge, denial and coverup. Whilst always having been a feature of the lives of adopted people, the issue of the late discovery of adoption is just one of the more recent of an accumulating legion of the challenges thrown up by myth and secrecy in adoption. Does the emergent research help us come to grips with this?

\section{2. "If They Can Keep This a Secret from Me, What Else Are They Not Telling Me?"}

Most of the writings on late discovery are personal experiences of adopted people, too many to enumerate here except to say that entering "late discovery adoptee" as a search term brings up over 7000 media stories, dedicated websites and support group forums and individual accounts, some in journals, others as stand alone. ' 'One woman's story of the trauma of discovering at midlife that she'd been adopted' https: / / severancemag. com/a-dna-test-revealed-im-a-late-discovery-adoptee/ (2020) (accessed on 31 October 2021) is not untypical. Research papers that deal directly with the subject are much less in evidence, indeed, just three papers and a report could be found using the search phrase 'late discovery' combined with 'adopted adult', 'adoptee'. The first is that of Perl (2000), which consists of a telephone and in-person interview with 40 adopted people. Riley's work, also with Australian adult adoptees, (Riley 2008, 2009, 2013) consists of the analysis of 22 accounts of late discovery of adoption. The third, to date the more extensive paper, is that of Baden et al. (2019) and involved a survey of 254 adopted adults, nearly half of whom had found out about their adoption after the age of 11, with 92 finding out after turning 21 years old (one informant found out about their adoption when they were 78 yrs. old). A fourth publication of note is the Australian Government's report into a study of past adoption practices. Eight hundred and twenty-three adopted people took part in the quantitative phase of this study. Ninety-four respondents (11\%) did not find out they had 
been adopted until they were 21 years of age or older. A further 70 adopted people found out between the ages of 11 and 20 years old (Kenny et al. 2012).

The paucity of the knowledge basis means that, undoubtedly, there is more to be said about the experiences and feelings of those who late-discover they have been adopted, however, five key themes and one issue appear in the existing literature. The issue in question is that of the number of people affected.

\section{How Many Might Be Affected by the Late Discovery That They Are Adopted?}

Based upon Riley's finding that $11 \%$ of her study of adopted adults had discovered in later life that they were adopted and on an estimate of 5 million adopted people in the USA, Baden et al. calculated that ' 550,000 U.S. adoptees, likely experienced delayed adoption disclosure or even nondisclosure altogether' (Baden et al. 2019, p. 1157). If Mignot's calculations relating to Western Europe (Mignot 2017) are used, then between 1900 and 2021, there have been 19,000 adoptions. Using the proportion of $11 \%$ as a guide, it would seem then that for this period, in Western Europe, over 200,000 people may have experienced late news of their adoption or none at all. ${ }^{5}$ Given that Mignot's figures date from 1900, it will be likely that there will be less than 200,000 such adopted people alive now, however, their descendants will be, and as will be suggested, the ripples from late discovery can be extensive. However, let us now return to the event of late discovery itself. The following five themes of shock, betrayal, realisation of denial of difference, losses and legacies are derived from Riley $(2008,2009,2013)$ and Baden et al. (2019) and in no hierarchical order. Though it seems right to begin with the event of the discovery.

\section{Shock of Discovery}

Riley comments that 'Late discoverers find out the truth of their origins in myriad ways. They find out by accident, are told by strangers, informed begrudgingly by family due to external pressures, and/or to cause pain or with insensitivity' (Riley 2013, p. 5). One of the informants in the Australian study by Kenny et al. testified thus:

"When I found out I was adopted, it came completely out of the blue as a note on a birthday card sent from an aunt [by marriage], telling me that although I was adopted, I would always be her nephew. From this point, my life was shattered; the life I had been living up till now was a complete lie". (Kenny et al. 2012, p. 90)

At the same time as the shock, there is the additional feeling that everyone else knew of their adopted status except them: 'Barbara' (quoted in Riley) ' ... was 27 years old, and five months pregnant, when her mother admitted to her adoption during an ironing session' and she is quoted:

“... Yes, local shop-keepers, neighbours, school friends and just about anyone who knew us was aware of this 'secret'". (Riley 2013, p. 5)

Another prominent contemporaneous emotion is that of having been deceived.

\section{Betrayal}

Finding out adoptive status 'accidentally or from a stranger merely adds a further dimension of perceived betrayal to an already fraught emotional situation' (Riley 2013, p. 5). One of Riley's informants in an earlier study spoke of being “ ... the brunt of a 40 year joke" ('Karla', in Riley 2009, p. 152). Two of the informants in one of the other Australian studies spoke of the discovery as meaning 'that my entire life up to the age of 49 was a lie' (Kenny et al. 2012, p. 90) and 'Devastated. My whole life was a lie. I never got over it' (Kenny et al. 2012, p. 90). The theme of deceit reaches back not just many years but in a perverse manner helps explain hitherto puzzling undercurrents in family dynamics. 


\section{The Conspiracy of Silence and Denial of Difference-Yet Unsurprised}

Riley found that many were not surprised by the news of their adoption. The majority of the adopted people in her study reported that they had never felt they fitted in their families:

Most had usually looked different from the rest of their families, and had always felt that they were different in other ways, as well. Being told that they were adopted only confirmed pre-existing feelings and intuitions of being "other". (Riley 2013, p. 10)

Though unsurprised by the news, the task of comprehending the depth of dishonesty and lack of integrity and responsibility that has gone on through childhood, adolescence and adulthood is considerable and undoubtedly a contribution to the immediate distress at the point of late discovery. If there is any mitigating factor, there may be some relief from knowing that feelings of being the odd one out, the awkwardness felt at family gatherings and the evasions experienced when questions of family roots and histories arose can now be explained. These discomforts were not the fault of the adopted person.

Whilst feelings of shock and betrayal and distress over the extent of deceit may become less keen, there are some major losses that are not so diluted.

\section{Losses: Kinship Confusion}

In her study of Scottish adopted people and kinship, Carsten observes that:

The constitutive power of new kinship knowledge might be reinforced when such knowledge has been concealed. And this is because identity for Euro-Americans rests not just with self- knowledge, and hence kinship knowledge, but also with a sense of control over one's own life. (Carsten 2007, pp. 421-22).

In other words, knowledge of one's roots is essential to feel 'whole'. For those who discover they are adopted, this 'anchoring' sense of kinship is erased with all the turmoil and confusion that can be imagined from that.

Of those adopted people in her study, Perl noted that 'Some of the sample also experienced feelings of loss that their family was not their biological family, and questions of "who am I?" overwhelmed them' (Perl 2000, p. 3), and one of Kenny et al.'s informants: "... felt I did not belong and was constantly confused about the way I was treated by my parents" (Kenny et al. 2012, p. 99). The third of the Australian studies on late-discoveries points out that those who experience this 'Not only do they have the family they grew up with, there is now another family 'out there', consisting of biological kin they know nothing about' (Riley 2013, p. 7). In Riley's earlier work, she quotes 'Zoe's' sorrow that finding out about her adoption in her forties left:

“... little time to try to find any birth parents ... I did manage to meet my birth mother, and two sisters, but it was all too late. My birth mother was very old and sick ... incoherent ... and my birth sisters had had seriously sad and difficult lives". (Riley 2009, p. 153)

This is followed closely by Ursula's account of feeling adrift: “ . . the most serious injustice afforded to me by late disclosure is that it prevented me from meeting my father and other members of my paternal family and developing a meaningful relationship with them during his lifetime" (Riley 2009, p. 153). This leads us to the next aspect of loss, agency.

\section{Losses: Agency}

The late discovery of adoption forces, produces and brings to the surface deep-seated identity questions. Perl talks of a grieving 'for the person whom one thought one was' (Perl 2000, p. 5). Kenny et al.'s informants echo this experience of loss of self: "It was as if my history was no longer mine ... ", and "Shocked, disbelieving, foolish, sense of self identity shattered". (Kenny et al. 2012, p. 90); a later informant in the same study was more blunt: "Upon disclosure, a big black hole opened up for me-“"Who was I really?"” (Kenny et al. 2012, p. 99). 
Riley suggests that those who discover their adopted then feel that ' ... they have had a 'false' identity imposed upon them; that they could have and probably would have grown and developed differently if they had been in possession of this knowledge about themselves ...' (Riley 2013, p. 9).

\section{Losses: Culture}

Whilst all of us have cultures into which we are born and from which we come, for some of those who discover they are adopted, there can be broader range of consequences and complexity of losses. In Riley's study, 'Markus' discovered he was of aboriginal heritage: "I had fair skin and didn't know I was of Aboriginal descent" (Riley 2013, p. 9). Riley goes on to observe that the complexity of his discovery demanded an even greater intensity of re-orientation of his worldview and sense of self than others who did not have such specific cultural and ethnical bio-familial roots. This meant that alongside the decisions and tasks with which other late-discovery people had to engage such as learning about and searching for biological kin, this, for 'Markus', also encompassed 'learning about a new culture, a history of oppression ... ' and the systemic indignities to which his people had suffered (Riley 2013, p. 9).

Losses for late-discovery people can also be practical.

\section{Losses: Medical History}

Consider the chasm of health and medical and genetic knowledge that suddenly opens up on late discovery that the blood line that you thought you had was a fiction. This is closely coupled with the realisation that 'out there' there is another repository of information that is yours-but only if you can source it. 'Tina', one of Riley's informants, " ... found there was a history of mental illness in my natural family". She goes on, "Another thing I found out which really devastated me was there was a severe hearing problem in my family and I needed hearing aids immediately at the age of 33" (Riley 2013, p. 8).

Betrayed, conspired against and suffering multiple losses that range from the existential to vital practical health information. Add the fact that all of this might be experienced, felt, sensed and inflicted in seconds. If one can speak of an aftermath and consequences of late discovery, what might be a feature of the subsequent lives of these adopted people?

\section{Legacies}

Baden et al. suggest that experiences of late discovery have long-term consequences for relationships with others. Such experiences ' ... have the power to create ... interpersonal conflicts with others due to mistrust and other negative emotions and quote one informant who was aged 49 at the age of discovery':

"Realizing that you don't know who you are is life changing. Every relationship in my life changed at that moment. I am much more guarded in every aspect now. Finding out that everyone knew and I didn't is probably the single most traumatic event in my life". (Baden et al. 2019, p. 1171)

Baden et al. also draw attention to intrapersonal effects such as psychological distress: 'The adult adoptees in this study reported that learning of their adoption status as adults was significantly related to increased psychological distress even when measured many years after the adoption disclosure' (Baden et al. 2019, p. 1172).

\section{Final Observations}

Clearly, research on the experiences of the late discovery of adoptive status is in its infancy, certainly compared to the extent of Internet activity on the subject. What we can derive from the few existing works is that the late discovery of adoption can be considerably negatively significant for that adopted person's well-being and social relationships, and that late-discovery has long-term and lasting detrimental effects.

The obvious parallel with the experiences of people who discover they are adopted is that of those who have been conceived by donor. Riley (2013) and Baden et al. (2019) 
make this connection. Our knowledge that considerably more donor-conceived adults have their status concealed from them than adopted adults (Daniels et al. 2009) means that further down the line, notwithstanding the international trends for the reversal of donor anonymity (Blyth and Frith 2013), sooner rather than later, there will be a similar burgeoning of research relating to the experiences of late-discovery of origins in this group of people.

Understandably there are gaps in the literature. Yet to be examined are the effects of late-discovery on others. The literature tends to treat those affected as atomised individuals, that is, adults without children (or grandchildren) or partners. We have yet to understand the effects on the lives of others close to an adopted person of late discovery. Indeed, what if the descendants of a deceased adopted person make the late discovery? DNA websites and services make this increasingly likely. Baden et al. (2019) observe that perhaps the later in life that one learns of her/his adoptive status the better because greater maturity can bring better coping skills-as compared with someone who learns that they are adopted when they are in their late teens. However, what about the timing and event-specific contexts of these discoveries? That is not just late in adult life compared with early adulthood, but how does late discovery effect, for example, someone undergoing a bereavement? Or a wedding? Or the birth of their child? One imagines, yes, of course, in all three examples, but that said, just how? On the one hand, there may be only so much a person can endure, mature adult or not, before they entertain darker thoughts of life's injustices. On the other hand, what of the pleasure that can be ushered in at a birth (or wedding)-what is to become of this when a late discovery lands on top of it? Finally, how late-discovery of being adopted differently affects men and women awaits research.

These gaps aside, it is clear from what we know already that whilst family histories are complex at the best of times, the late discovery of being adopted compounds this a thousand-fold.

Funding: This research received no external funding.

Institutional Review Board Statement: Not applicable.

Informed Consent Statement: Not applicable.

Data Availability Statement: Not applicable.

Conflicts of Interest: The author declares no conflict of interest.

\section{Notes}

1 Studying trends in adoption as reflected in films will have to wait for another paper.

2 This is not to say that prior to the 1970s adult adoptees were not visible in the discourses around adoption, see, for example, (Paton 1954).

3 Other social factors that stand out once the span of adoption is considered include the rise of inter-country adoption, for example, as a result of a relative decline in the availability of white babies in the USA, adoptions of South Korean children increased from the 1970s. These adoptions in turn have produced the kind of fluctuating attention described here. For example, South Korea was the highest ranking country sending children for adoption overseas in the years 1980-1989 (Selman 2009). Once these children began to reach adulthood and articulate their experiences, the pace of public attention increased (Nelson et al. 2007). This is not to say that earlier experiences of Korean adoptees have not found their way into print. Jane Trenka was born in 1972, and her 2003 memoir of growing up adopted in rural Minnesota is widely acclaimed (Trenka 2003).

The term 'late discovery adoptee' seems to have been coined by Morgan in the mid-1990s. His blog post (written under his name BB Church) provides a summary of the genesis of interest in the subject: http://bbchurch.blogspot.com/2006/05/ (accessed 31 October 2021).

5 In Mignot's paper, 'Western Europe' is restricted to Germany, Sweden, France, England and Wales and Italy. Furthermore, given that the most recent decades have seen a major decline in the adoptions of babies (and a rise in adoptions of older children, holmanand not be subject to the kind of late-discovery experiences undergone by older adopted people. The percentage of $11 \%$ ought to thus be taken as broad guide rather than precise application because the percentage of late-discoveries will be less for adopted people under 30 years old and more for those over this age. 


\section{References}

Baden, Amanda, Doug Shadel, Ron Morgan, Ebony White, Elliotte Harrington, Nicole Christian, and Todd Bates. 2019. Delaying Adoption Disclosure: A Survey of Late Discovery Adoptees. Journal of Family Issues 40: 1154-80. [CrossRef]

Blyth, Eric, and Lucy Frith. 2013. International Policy Trends Surrounding Donor Anonymity and Disclosure of Donor-Conceived Status. In Donor Conception: Lessons for Clinicians, Families, Policy Makers and Researchers, 20-21 June 2013, Montreal, Canada. (Unpublished). Available online: http:/ / eprints.hud.ac.uk/id/eprint/18518/ (accessed on 31 October 2021).

Carsten, Janet. 2007. Connections and Disconnections of Memory and Kinship in Narratives of Adoption Reunions in Scotland. In Ghosts of Memory: Essays on Remembrance and Relatedness. Edited by Janet Carsten. Oxford: Blackwell.

Clapton, Gary. 1996. No more secrets and lies. Community Care, November 7, p. 27.

Daniels, Ken, Wayne Gillett, and Victoria Grace. 2009. Parental Information sharing with donor insemination conceived offspring: A follow-up study. Human Reproduction 24: 1099-105. [CrossRef] [PubMed]

Fisher, Florence. 1973. The Search for Anna Fisher. New York: A. Fields Books.

Kenny, Pauline, Daryl Higgins, Carol Soloff, and Reem Sweid. 2012. Past Adoption Experiences: National Research Study on the Service Response to Past Adoption Practices; Melbourne: Australian Institute of Family Studies.

Knight, Robert. 1941. Some Problems in Selecting and Rearing Adopted Children. Bulletin of the Menninger Clinic 5: 65-74.

Mignot, Jean-François. 2017. Full adoption in England and Wales and France: A comparative history of law and practice (1926-2015). Adoption E Fostering 41: 142-58.

Nelson, Kim Park, Elena Kim, and Leyne Myong Petersen. 2007. Proceedings of the First International Korean Adoption Studies Research Symposium. Dongguk University, Seoul, South Korea. Available online: http://kimparknelson.org/wp-content/ uploads /2016/02/ikaa-final-2.pdf (accessed on 31 October 2021).

Paton, Jean. 1954. The Adopted Break Silence: Forty Men and Women Describe Their Search for Natural Parents. Philadelphia: Life History Study Center.

Pelz, Stephen. 1990. On systematic explanation in international history. International History Review 12: 762-78. [CrossRef]

Perl, Lynne. 2000. Why wasn't I told? Making sense of the late discovery of adoption. The Benevolent Society of New South Wales: Paddington, NSW Australia. Available online: https://www.americanadoptioncongress.org/docs/801\%20-\%20why-wasnt-itold-may2001.pdf (accessed on 20 October 2021).

Raleigh, Barbara. 1954. Adoption as a factor in child guidance. Smith College Studies in Social Work 25: 53-71. [CrossRef]

Riley, Helen. 2008. The late discovery of adoptive status. Family Relationships Quarterly 7: 13-15.

Riley, Helen. 2009. Listening to late discovery adoption and donor offspring stories: Adoption, ethics and implications for contemporary donor insemination practices. In Other People's Children: Adoption in Australia. Edited by C. Spark and D. Cuthbert. Melbourne: Australian Scholarly Publishing, pp. 145-60.

Riley, Helen. 2013. Confronting the conspiracy of silence and denial of difference for late discovery adoptive persons and donor conceived people. Australian Journal of Adoption 7: 1-13.

Sants, Harriet. 1964. Genealogical bewilderment in children with substitute parents. British Journal of Medical Psychology 37: 133-40. [CrossRef] [PubMed]

Selman, Peter. 2009. The movement of children for international adoption: Developments and trends in receiving states and states of origin. 1998-2004. In International Adoption: Global Inequalities and the Circulation of Children. Edited by Diana Marre and Laura Briggs. New York: New York University Press, pp. 32-51.

Trenka, Jane. 2003. The Language of Blood: A Memoir. St Paul: Minnesota Historical Society Press. 